\title{
Fósforo no solo e desenvolvimento de soja influenciados pela adubação fosfatada e cobertura vegetal
}

\author{
Juliano Corulli Corrêa(1), Munir Mauad( ${ }^{(1)}$ e Ciro Antônio Rosolem ${ }^{(1)}$ \\ (1)Universidade Estadual Paulista, Fac. de Ciências Agronômicas, Fazenda Experimental Lageado, Caixa Postal 237, CEP 18603-970 Botucatu, \\ SP. E-mail: correajc@fca.unesp.br, mauad@laser.com.br, rosolem@fca.unesp.br
}

\begin{abstract}
Resumo - A eficiência agronômica dos adubos fosfatados pode ser afetada pelas fontes de fosfato, propriedades do solo, modos de aplicação e espécies vegetais. O objetivo deste trabalho foi avaliar o efeito de doses de fósforo e resíduos de plantas de cobertura na dinâmica do fósforo no solo e no desenvolvimento inicial da soja. O experimento foi realizado em casa de vegetação, em vasos com material de um Latossolo Vermelho distrófico. Os tratamentos constituíram-se de três palhadas, milheto, aveia e sorgo-de-guiné, simulando a cobertura do solo, na quantidade de $8 \mathrm{t} \mathrm{ha}^{-1}$ de massa de matéria seca, interagindo com $0,50,100$ e $150 \mathrm{~kg} \mathrm{ha}^{-1}$ de $\mathrm{P}$, aplicados sobre a palhada, na forma de superfosfato simples. As doses de $\mathrm{P}$ e os diferentes tipos de palha influenciaram a dinâmica do P no solo. A cobertura com milheto foi mais eficiente na lixiviação do P disponível, enquanto as coberturas com aveia e sorgo-de-guiné foram mais eficientes em lixiviar o P orgânico.
\end{abstract}

Termos para indexação: Glycine max, plantio direto, plantas de cobertura.

\section{Phosphorus in soil and soybean growth as affected by phosphate fertilization and cover crop residues}

\begin{abstract}
The efficiency of phosphate fertilizers can be affected by phosphate sources, soil properties, way of application and plant species. The objective of this work was to evaluate the effect of phosphorus levels and cover crops residues on phosphorus dynamics in the soil and soybean initial growth. The experiment was carried out in a greenhouse in pots containing a dystrophic Red Latosol (Typic Hapludox). The treatments consisted of three cover crop residues: pear millet (Penisetum americanum L.), oats (Avena strigosa) and guinea sorghum (Sorghum bicolor) at $8 \mathrm{t} \mathrm{ha}^{-1}$, interacting with $0,50,100$ and $150 \mathrm{~kg} \mathrm{ha}^{-1}$ of P, applied over straw mulch, as simple superphosphate. Phosphorus levels and the different residues affected $\mathrm{P}$ transport through the soil. Pear millet was more efficient in leaching available $\mathrm{P}$ while oats and guinea sorghum were more effective in leaching organic phosphorus.
\end{abstract}

Index terms: Glycine max, no-tillage, cover crops.

\section{Introdução}

O fósforo (P) é o nutriente mais limitante da produtividade de biomassa em solos tropicais (Novais \& Smyth, 1999). Os solos brasileiros são carentes de $P$, em consequiência do material de origem e da forte interação do P com o solo (Raij, 1991), em que menos de $0,1 \%$ encontra-se em solução (Fardeau, 1996).

A aplicação de $\mathrm{P}$ em doses elevadas em solos intemperizados é justificada pela intensa fixação desse elemento, ocasionando baixo conteúdo de $\mathrm{P}$ disponível, principalmente em solos onde há predomínio de minerais sesquióxidos (Büll et al., 1998; Novais \& Smyth, 1999). A eficiência agronômica dos adubos fosfatados pode ser afetada pelas fontes de fosfato, propriedades do solo, modos de aplicação e espécies vegetais (Chien \& Menon, 1995).

A aplicação de fertilizantes fosfatados em área total (fosfatagem), no sistema de plantio direto, tem sido realizada em superfície, sem incorporação. Por causa da presença da palhada e do maior nível de matéria orgânica, este manejo proporciona um ambiente menos oxidativo, fazendo com que as reações de fixação sejam minimizadas e que haja menor contato dos resíduos com o solo, promovendo impacto direto na fertilidade das camadas superficiais, até $10 \mathrm{~cm}$ de profundidade (Costa \& Rosolem, 2000). Portanto, todas as práticas 
de manejo que visam manter ou incrementar os níveis de matéria orgânica podem resultar em benefício no aproveitamento de $\mathrm{P}$ pelas plantas (Almeida et al., 2003).

As espécies vegetais são fundamentais na solubilização do $\mathrm{P}$, principalmente o P não-lábil, pois existem espécies que possuem capacidade de solubilizá-lo mediante a exsudação de suas raízes, a qual contém ácidos orgânicos, e estes, por sua vez, agem na dissolução do colóide, alimentando o P na solução do solo (Chien $\&$ Menon, 1995). No sistema de plantio direto, ocorre o aumento de matéria orgânica nos horizontes superficiais, em decorrência da deposição de palhada, decrescendo com a profundidade. Uma das principais características que influem na adsorção de P é a matéria orgânica (Gonçalves et al., 1985), a qual interage com os óxidos de $\mathrm{Al}$ e Fe resultando em redução dos sítios de fixação, por causa do recobrimento da superfície desses óxidos por moléculas de acidos húmicos, acético e málico, ou pela formação de compostos na solução do solo. Ocorre, assim, uma tendência de menor fixação e, portanto, maior aproveitamento pela planta do $\mathrm{P}$ oriundo da adubação fosfatada. Esse efeito, no entanto, é temporário (Fontes et al., 1992; Afif et al., 1995; Andrade et al., 2003).

A manutenção dos resíduos vegetais da parte aérea, pelo sistema de plantio direto, resulta em menor ação de decomposição microbiana, decorrente do menor contato com o solo. Assim, é possível ocorrer produção contínua de ácidos orgânicos, o que beneficia a aplicação superficial do calcário e fósforo, mediante a formação de complexos, reduzindo o alumínio e aumentando a mobilidade de $\mathrm{Ca}$ e $\mathrm{Mg}$, ficando esta ação restrita à camada de 2,5 cm do solo (Amaral et al., 2004).

Outra vantagem deste sistema é a melhor estruturação do solo, beneficiando a formação de galerias, oriundas da decomposição de raízes e da microfauna, pela qual caminharia a matéria orgânica e com ela o P orgânico e inorgânico (Raij, 1991; Chepkwony et al., 2001).

O objetivo deste trabalho foi avaliar o efeito de doses de fósforo e resíduos de plantas de cobertura na dinâmica do fósforo no solo e no desenvolvimento inicial da soja.

\section{Material e Métodos}

O experimento foi realizado no período de agosto a outubro de 2002, em casa de vegetação, na Faculdade de Ciências Agronômicas da Unesp, Campus de Botucatu, SP.
Foram utilizadas amostras deformadas de solo, provenientes da camada arável de um Latossolo Vermelho distrófico (Embrapa, 1999), textura franco arenosa, com as seguintes características químicas e granulométricas: $\mathrm{pH}\left(\mathrm{CaCl}_{2}\right), 4,2 ; \mathrm{MO}, 18,9 \mathrm{~g} \mathrm{dm}^{-3}$; $\mathrm{P}$ resina, $4,3 \mathrm{mg} \mathrm{dm}{ }^{-3} ; \mathrm{H}+\mathrm{AL}, 39,5 \mathrm{mmol}_{\mathrm{c}} \mathrm{dm}^{-3} ; \mathrm{K}$, 2,2 $\mathrm{mmol}_{\mathrm{c}} \mathrm{dm}^{-3} ; \mathrm{Ca}, 9 \mathrm{mmol}_{\mathrm{c}} \mathrm{dm}^{-3} ; \mathrm{Mg}, 3,6 \mathrm{mmol}_{\mathrm{c}} \mathrm{dm}^{-3}$; CTC, 54,2 $\mathrm{mmol}_{\mathrm{c}} \mathrm{dm}^{-3}$; V, 27\% (Raij et al., 2001); $690 \mathrm{~g} \mathrm{~kg}^{-1}$ de areia; $150 \mathrm{~g} \mathrm{~kg}^{-1}$ de silte e $160 \mathrm{~g} \mathrm{~kg}^{-1} \mathrm{de}$ argila.

Após a coleta das amostras, o solo foi peneirado em malha de $4 \mathrm{~mm}$ para separação de torrões, raízes e palha. Fez-se a calagem com calcário (PRNT de 78\%, $30 \%$ de $\mathrm{CaO}$ e $16 \%$ de $\mathrm{MgO}$ ) para elevar a saturação por bases a $70 \%$ e adubação com $120 \mathrm{mg} \mathrm{dm}^{-3}$ de K (KCl), $25 \mathrm{mg} \mathrm{dm}^{-3} \mathrm{de} \mathrm{N}$ (uréia), $2 \mathrm{mg} \mathrm{dm}^{-3}$ de B (bórax) e $6 \mathrm{mg} \mathrm{dm}^{-3} \mathrm{de} \mathrm{Zn}$ (sulfato de zinco). Após a colocação do solo nos vasos, o solo de cada vaso foi irrigado até $70 \%$ da capacidade de campo e mantido em incubação, sob lona de plástico, por vinte dias. Aplicaram-se em cobertura $50 \mathrm{mg} \mathrm{dm}^{-3}$ de $\mathrm{N}$ (uréia), aos 20 dias após a emergência das plantas.

$\mathrm{O}$ experimento foi instalado em esquema fatorial $3 \times 4$, em delineamento em blocos casualizados, com quatro repetições. Os tratamentos constituíram-se de três tipos de palhada, milheto (Pennisetum americanum L.), aveia (Avena strigosa Shieb) e sorgo-de-guiné (Sorghum bicolor L.), simulando a cobertura do solo, na quantidade de $8 \mathrm{t} \mathrm{ha}^{-1}$ de massa de matéria seca, e 0, 50, 100 e $150 \mathrm{~kg} \mathrm{ha}^{-1}$ de $\mathrm{P}$, aplicados sobre a palhada, na forma de superfosfato simples.

Os vasos constaram da sobreposição de cinco anéis de PVC rígido, com $15 \mathrm{~cm}$ de diâmetro interno, com as seguintes alturas: 7,5, 5, 5, 15 e $15 \mathrm{~cm}$; sendo os primeiros 2,5 cm separados para acomodar a palhada, encontrando-se, assim, camadas de 0-5, 5-10, 10-15, 15-30 e $30-45 \mathrm{~cm}$, totalizando $7,9 \mathrm{dm}^{3}$.

Foi determinada a curva de retenção de água do solo por meio de placas porosas, conforme Kiehl (1979). Com $60 \mathrm{~cm}$ de coluna, valor que melhor caracteriza a capacidade de campo, o solo apresentou $0,40 \mathrm{dm}^{3} \mathrm{dm}^{-3}$. Com base nesse valor, os vasos foram pesados, obtendo-se os valores de retenção de água no solo para a manutenção da umidade durante o experimento, mediante pesagens diárias e regas na superfície.

As espécies de cobertura, aveia, milheto e sorgo-deguiné, foram cortadas com 50 dias após a emergência, a campo, secadas em estufa com circulação de ar for- 
çada a $60^{\circ} \mathrm{C}$ por dois dias e, em seguida, seccionadas em pedaços de 2 a $3 \mathrm{~cm}$ e acomodadas nos primeiros $2,5 \mathrm{~cm}$ do vaso, em função da dose de $8 \mathrm{t} \mathrm{ha}^{-1}$. Foram cultivadas duas plantas de soja por vaso e, aos 50 dias após a emergência, no início do estádio de diferenciação floral, as plantas foram seccionadas no colo, separando a parte aérea do sistema radicular. Foram determinadas a produção de matéria seca da parte aérea e a produção de matéria seca de raízes, considerando separadamente cada uma das cinco camadas de solo. As raízes foram separadas do solo por lavagem em água sobre peneira de $0,5 \mathrm{~mm}$ de malha, manualmente. No solo, foram avaliados os teores de $\mathrm{P}$ extraído por resina (Raij et al., 2001) e de P orgânico (Catani \& Bataglia, 1968).

Os dados obtidos foram submetidos à análise de regressão, ajustando-se as equações a partir das doses de fósforo. Adotou-se como critério na escolha do modelo, a interação pelo teste $\mathrm{F}$ significativo a $5 \%$ e a magnitude dos coeficientes de determinação.

\section{Resultados e Discussão}

A massa de matéria seca da parte aérea da soja apresentou comportamento crescente, sendo que cada espécie de cobertura vegetal apresentou um tipo de característica em função do aumento das doses de $\mathrm{P}$ no solo (Figura 1). O sorgo-de-guiné favoreceu o crescimento da soja até a dose de $100 \mathrm{~kg} \mathrm{ha}^{-1}$ de fósforo. Tanto a aveia como o milheto apresentaram um comportamen-

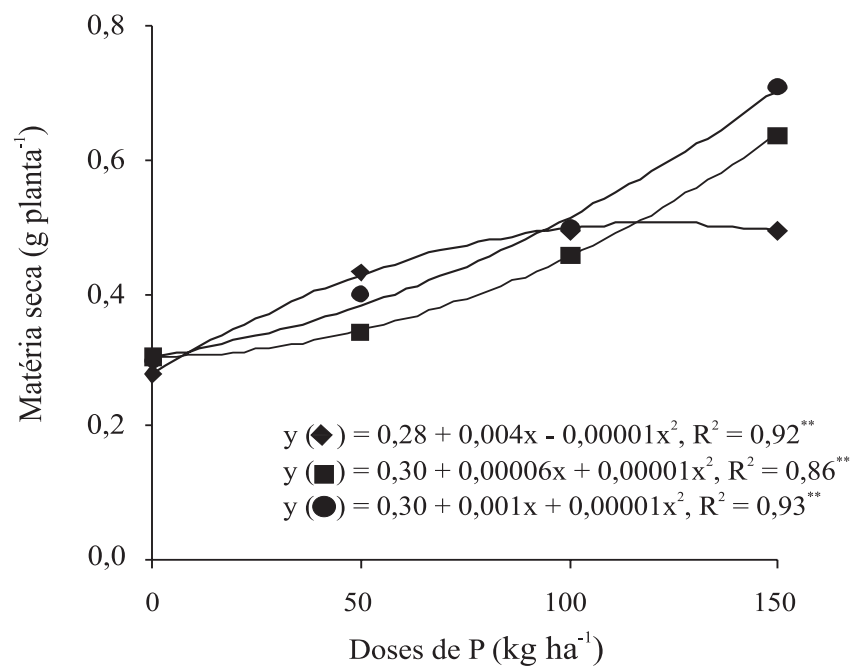

to quadrático, sem ponto de inflexão da curva, até a dose de $150 \mathrm{~kg} \mathrm{ha}^{-1}$. A aveia foi o tratamento mais eficiente no crescimento da soja nas últimas duas doses de fósforo. Uma das razões para o comportamento diferenciado do sorgo-de-guiné pode ser a presença de efeito alelopático desta espécie, prejudicando o crescimento da soja.

Quanto à matéria seca da raiz da soja, não houve diferença entre os tipos de palha (Figura 2). No entanto, com o aumento das doses de P, verificaram-se aumentos na produção de matéria seca de raiz de soja, com resposta significativa até a profundidade de $30 \mathrm{~cm}$. Até $15 \mathrm{~cm}$ de profundidade, houve resposta até a dose de $50 \mathrm{~kg} \mathrm{ha}^{-1}$ de $\mathrm{P}$, entretanto na camada de $15-30 \mathrm{~cm}$, a massa de matéria seca de raiz aumentou linearmente até a dose de $150 \mathrm{~kg} \mathrm{ha}^{-1}$ de fósforo.

$\mathrm{O}$ incremento das doses de $\mathrm{P}$ aplicadas em superfície aumentou os teores de $\mathrm{P}$ disponível no solo até a profundidade de $30 \mathrm{~cm}$, com as palhadas das três espécies, e na camada de $30-45 \mathrm{~cm}$, apenas com o milheto, proporcionando assim uma distribuição mais uniforme de $\mathrm{P}$ no solo com resíduos desta espécie (Figura 3). Aumentos nos níveis de $\mathrm{P}$ disponível no solo em função de doses do fertilizante fosfato foram também observados por Rosolem et al. (1994), Büll et al. (1998) e Rosolem \& Marcello (1998). Esse resultado se justifica pela capacidade de adsorção de $\mathrm{P}$ diminuir com o aumento da concentração deste elemento no solo (Whalen \& Chang, 2002), e da capacidade de adsorção dos colóides do solo

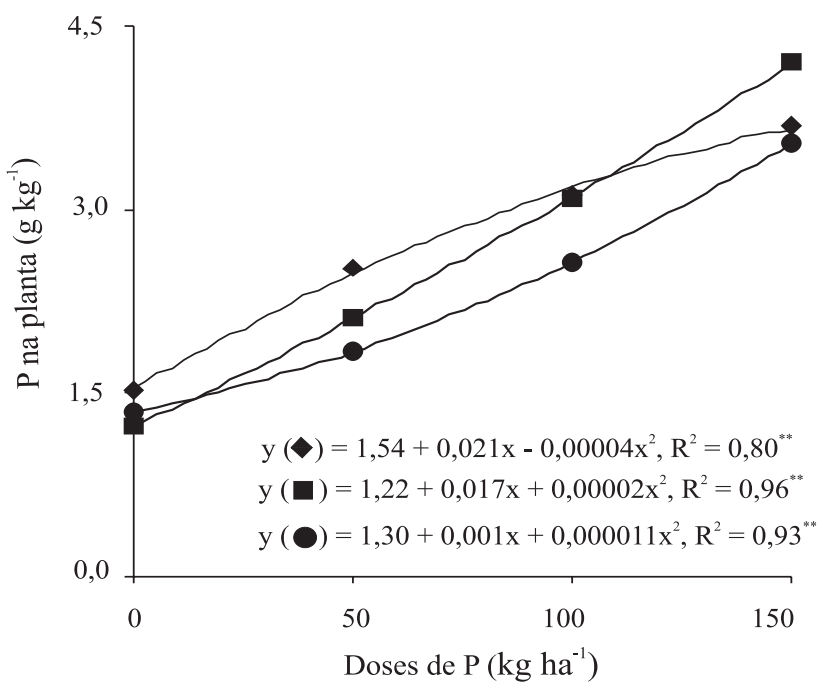

Figura 1. Matéria seca de planta e teor de fósforo na planta de acordo com doses de fósforo aplicadas sobre palhadas de sorgo-de-guiné $(\boldsymbol{O})$, milheto $(\boldsymbol{\square})$ e aveia $(\boldsymbol{\nabla})$. 
diminuir em presença dos ácidos orgânicos liberados pela palha em superfície (Franchini et al., 2001).

Houve movimentação do $\mathrm{P}$ em profundidade, com características distintas para cada espécie, pois, na camada mais profunda, apenas o milheto proporcionou maiores teores de fósforo (Figura 3). A velocidade de liberação de nutrientes dos resíduos culturais durante o processo de decomposição depende das características da espécie, em especial da relação $\mathrm{C} / \mathrm{N}$ e da localização e da forma em que esses nutrientes se encontram no tecido vegetal (Giacomini et al., 2003). No caso do $\mathrm{P}$, cuja maior parte encontra-se na planta associada a componentes orgânicos do tecido vegetal (Marschner, 1995), sua liberação está intimamente ligada ao processo de decomposição pelos microrganismos do solo. Na dose zero de $\mathrm{P}$, maiores teores do nutriente disponível no solo sob as palhas de sorgo-de-guiné e aveia, até a profundida- de de 30-45 cm, foram verificadas (Figura 3). A dose mínima de fertilizante aplicada, $50 \mathrm{~kg} \mathrm{ha}^{-1}$, foi suficiente para mascarar este efeito.

Diferenças entre teores de P no solo em função do tipo de palha podem ser explicadas considerando-se também a composição química de cada espécie. Os ácidos orgânicos podem estar correlacionados à percolação do $\mathrm{P}$ ao longo do perfil do solo, sendo que os mesmos são produzidos de acordo com o tipo de planta e com o estresse que esta sofre ao longo do ciclo (Gaume et al., 2001). Estes resultados estão de acordo com Santos \& Tomm (1996), que avaliaram cinco sistemas de rotação, verificando diferenças significativas de $\mathrm{P}$ extraível na maioria das profundidades estudadas.

Os menores teores de $\mathrm{P}$ disponível nos vasos com palha de sorgo-de-guiné, na camada mais profunda (Figura 3), não podem ser atribuídos a uma maior absor-
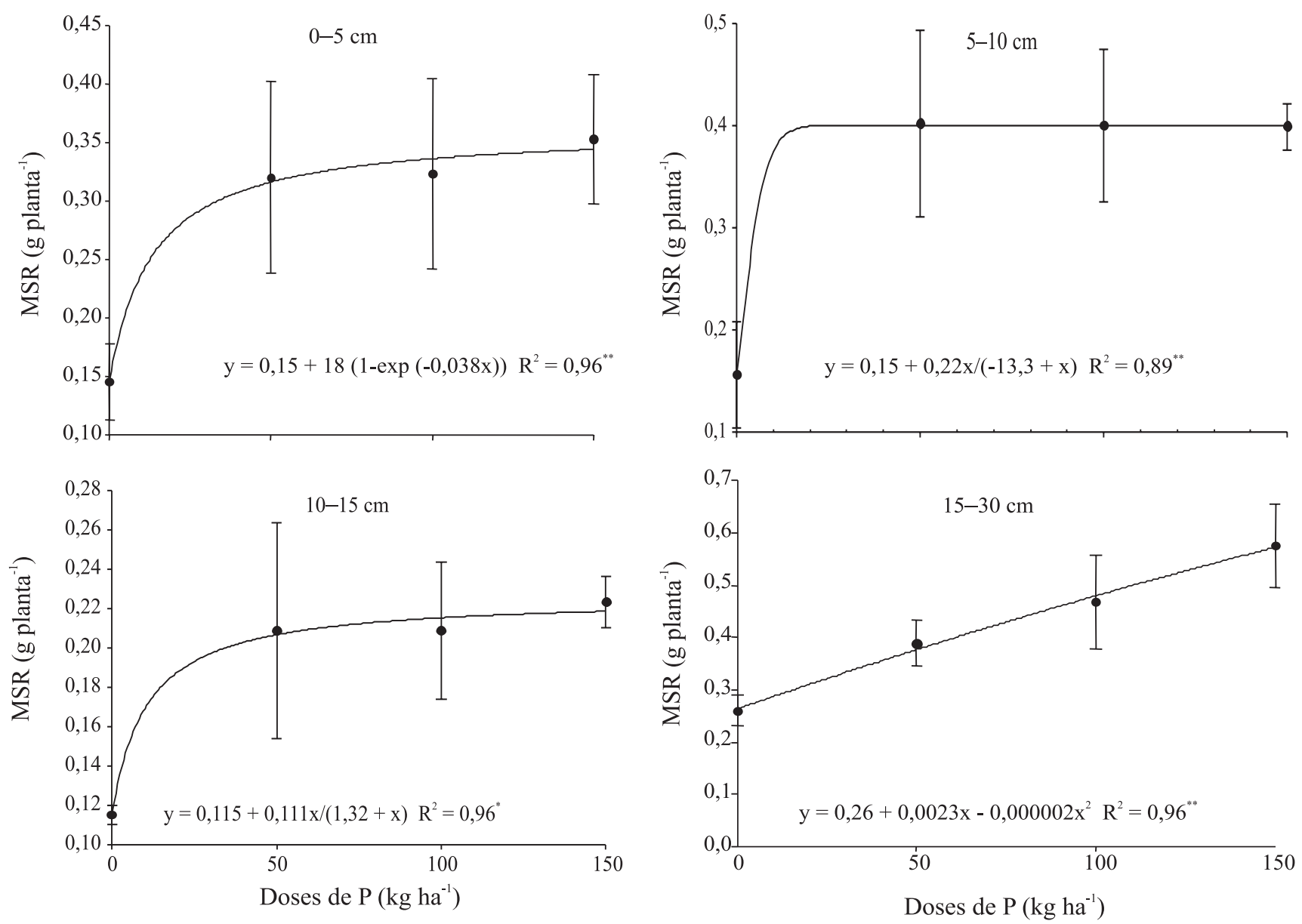

Figura 2. Relação entre a massa de matéria seca de raiz da soja (MSR) e as doses de fósforo aplicadas no solo, nas diferentes

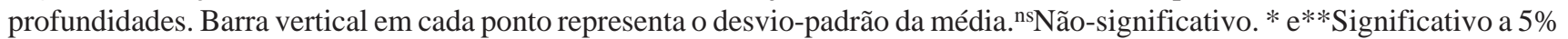
e a $1 \%$ de probabilidade pelo teste $\mathrm{F}$, respectivamente. 

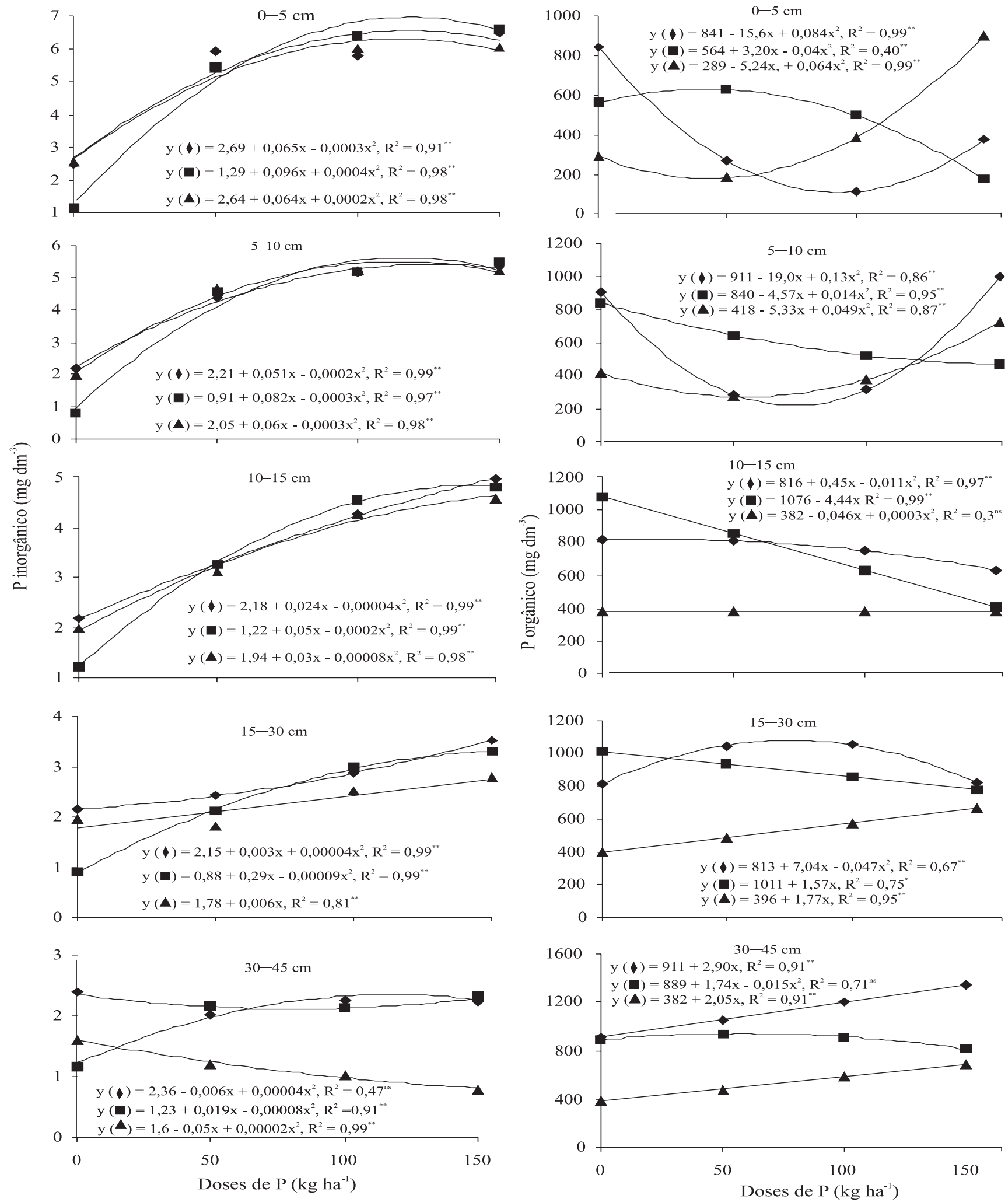

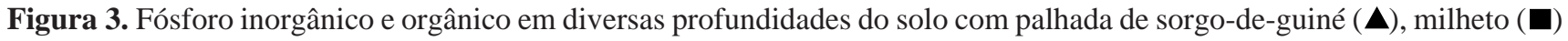
e aveia $(\diamond)$, de acordo com doses de fósforo. 
ção de P pela planta, uma vez que, principalmente com a maior dose de $\mathrm{P}$, a soja produziu mais e absorveu mais quando cultivada em palhadas de aveia e de milheto (Figura 1). Deste modo, pode-se inferir que o milheto e a aveia promoveram maior distribuição do nutriente no solo que o sorgo-de-guiné, com exceção do tratamento de milheto com dose zero de fósforo. Isso pode ser atribuído às diferenças no conteúdo de ácidos orgânicos de cada espécie, induzindo benefícios de aumento de $\mathrm{pH}$, $\mathrm{Ca}, \mathrm{Mg}$ e $\mathrm{K}$ e redução de $\mathrm{Al}$, em especial na aveia (Franchini et al., 2003).

Além disso, a melhor distribuição do $\mathrm{P}$ disponível no perfil do solo pode ser uma das razões para a maior absorção do nutriente e melhor crescimento da soja nos tratamentos com maiores doses deste nutriente, quando cultivada sobre aveia e milheto. $\mathrm{O}$ sistema radicular da soja respondeu ao incremento de doses até $50 \mathrm{~kg} \mathrm{ha}^{-1}$ de $\mathrm{P}$ na profundidade de $15 \mathrm{~cm}$ e até $150 \mathrm{~kg} \mathrm{ha}^{-1}$ de $\mathrm{P}$ na profundidade de 15-30 cm (Figura 2). Estas doses corresponderam, respectivamente, a aproximadamente 5 e $6 \mathrm{mg} \mathrm{dm}^{-3} \mathrm{de}$ P, na profundidade até $15 \mathrm{~cm}$. Na profundidade de $15-30 \mathrm{~cm}$, os teores de $\mathrm{P}$ nunca chegaram a estes valores, justificando a resposta linear. Rosolem \& Marcello (1998) demonstraram que $8,0 \mathrm{mg} \mathrm{dm}^{-3}$ de $\mathrm{P}$ é mais do que suficiente para o crescimento radicular da soja. Assim, o sorgo-de-guiné pode ter limitado o crescimento e absorção de P pela soja mediante efeito alelopático, ou, mais provavelmente, pela pior distribuição do $\mathrm{P}$ no solo. Este efeito não aparece quando se analisa os resultados de produção de massa de matéria seca de raízes. No entanto, Rosolem et al. (1995) demonstraram que, em solos pobres em P, fatores relativos ao solo são mais limitantes ao crescimento da planta que as características da planta.

Com relação ao $\mathrm{P}$ orgânico, os resultados foram inconclusivos até a profundidade de $15 \mathrm{~cm}$. Entretanto, houve aumento dos valores dessa forma de $\mathrm{P}$ em profundidade, em função da aplicação do fertilizante, com as palhas de aveia e sorgo-de-guiné quando comparadas ao milheto (Figura 3). A aplicação de superfosfato não causa acúmulo de $\mathrm{P}$ orgânico em solos, mas aumenta a concentração de $\mathrm{P}$ das formas mais lábeis e reduz as formas mais estáveis, como o P orgânico (Perrott \& Mansell, 1989). Assim, pode-se inferir que tanto a palha de aveia como a de sorgo-de-guiné promoveram a lixiviação do $\mathrm{P}$ do fertilizante aplicado superficialmente. A capacidade de neutralização da acidez do solo por resíduos vegetais está associada aos teores de cátions e carbono orgânico, sendo o efeito do milheto quase nulo (Miyazawa et al., 1993), enquanto a aveia apresenta eficiente efeito de neutralização (Franchini et al., 2001). Como o pH do solo influi diretamente na mineralização da $\mathrm{MO}$ e adsorção de $\mathrm{P}$, poderia ter sido um fator para explicar este resultado. Entretanto, não pode ser descartada a hipótese de ter ocorrido contribuição dos ácidos orgânicos das palhas mantidas em superfície.

A resina extraiu uma parcela de $\mathrm{P}$ orgânico, e o seu aumento em profundidade não se refletiu nos teores de $\mathrm{P}$ disponível em profundidade (Figura 3). Assim, o P lixiviado no solo não estaria prontamente disponível às plantas.

$\mathrm{O}$ incremento das doses de $\mathrm{P}$ no solo aumentou os teores desse nutriente na planta (Figura 1). A cobertura de sorgo-de-guiné apresentou os maiores teores de $\mathrm{P}$ na planta até a dose de $100 \mathrm{~kg} \mathrm{ha}^{-1} \mathrm{de} \mathrm{P}$, o que resultou em maior crescimento da soja, até esta dose. A palhada do milheto foi mais eficiente na absorção de $\mathrm{P}$ com a maior dose do fertilizante, provavelmente por causa da melhor percolação e permanência do P disponível ao longo do solo, principalmente nas camadas de $15-30$ e $30-45 \mathrm{~cm}$. Como a aveia proporcionou a lixiviação do $\mathrm{P}$ no perfil, permitiu o maior crescimento da soja (Figuras 1 e 3), de modo que pode ter ocorrido um efeito de diluição dos teores do nutriente (Figura 1).

\section{Conclusões}

1. As espécies de cobertura influenciam a movimentação do fósforo em profundidade no solo.

2. A cobertura de milheto é mais eficiente na lixiviação do fósforo disponível, enquanto as coberturas de aveia e o sorgo-de-guiné são mais eficientes em lixiviar fósforo orgânico.

3. O sistema radicular da soja responde até 15 e $30 \mathrm{~cm}$, em função de 50 e $150 \mathrm{~kg} \mathrm{ha}^{-1}$ de fósforo, respectivamente, não apresentando diferença entre as espécies de cobertura.

4. A massa de matéria seca da parte aérea da soja aumenta tanto em função das doses de fósforo como das espécies de cobertura; a dose de $150 \mathrm{~kg} \mathrm{ha}^{-1}$ é a mais eficiente e, entre as espécies, a que mais favorece o crescimento da soja é a aveia, nesta mesma dose.

\section{Referências}

AFIF, E.; BARRON, V.; TORRENT, J. Organic matter delays but does not prevent phosphate sorption by cerrado soils from Brazil. Soil Science, v.159, p.207-211, 1995. 
ALMEIDA, J.A.; TORRENT, J.; BARRÓN, V. Cor de solo, formas de fósforo e adsorção de fosfatos em Latossolos desenvolvidos de basalto do extremo sul do Brasil. Revista Brasileira de Ciência do Solo, v.27, p.985-1002, 2003.

AMARAL, A.S.; ANGHINONI, I.; DESCHAMPS, F.C. Resíduos de plantas de cobertura e mobilidade dos produtos da dissolução do calcário aplicado na superfície do solo. Revista Brasileira de Ciência do Solo, v.28, p.115-123, 2004.

ANDRADE, F.V.; MENDONÇA, E.S.; ALVAREZ VENEGAS, V.H.; NOVAIS, R.F. Addition of organic and humic acids to Latosols and phosphate adsorption effects. Revista Brasileira de Ciência do Solo, v.27, p.1003-1011, 2003.

BÜLL, L.T.; FORLI, F.; TECCHIO, M.A.; CORRÊA, J.C. Relação entre fósforo extraído por resina e resposta da cultura do alho vernalizado à adubação fosfatada em cinco solos com e sem adubação orgânica. Revista Brasileira de Ciência do Solo, v.22, p.459-470, 1998.

CATANI, R.A.; BATAGLIA, O.C. Formas de ocorrência de fósforo no solo Latossólico Roxo. Anais da ESALQ, v.25, p.99-119, 1968.

CHEPKWONY, C.K.; HAYNES, R.J.; SWIFT, R.S.; HARRISON, R. Mineralization of soil organic $\mathrm{P}$ induced by drying and rewetting as a source of plant-avaliable $P$ in limed and unlimed samples of an acid soil. Plant and Soil, v.234, p.83-90, 2001.

CHIEN, S.H.; MENON, R.G. Factors affecting the agronomic effectiveness of phosphate rock for direct application. Fertilizer Research, v.41, p.227-234, 1995.

COSTA, A. Doses e modos de aplicação de calcário na implantação de sucessão soja-trigo em sistema de plantio direto. 2000. 146p. Tese (Doutorado) - Universidade Estadual Paulista, Botucatu.

EMBRAPA. Centro Nacional de Pesquisa de Solos (Rio de Janeiro, RJ). Sistema brasileiro de classificação de solos. Brasília: Embrapa-SPI; Embrapa-CNPS, 1999. 412p.

FARDEAU, J.C. Dynamics of phosphate in soils: an isotopic outlook. Fertility Research, v.45, p.91-100, 1996.

FONTES, M.R.; WEED, S.B.; BOWEN, L.H. Association of microcrystalline goethite and humic acid in some Oxisols from Brazil. Soil Science Society of America Journal, v.56, p.982-990, 1992.

FRANCHINI, J.C.; GONZALEZ-VILA, F.J.; CABRERA, F.; MIYAZAWA, M.; PAVAN, M.A. Rapid transformations of plant water soluble organic compounds in relation to cation mobilization in an acid Oxisol. Plant and Soil, v.231, p.55-63, 2001.

FRANCHINI, J.C.; HOFFMAN-CAMPO, C.B.; TORRES, E.; MIYAZAWA, M.; PAVAN, M.A. Organic composition of green manure during growth and its effects on cation mobilization in an acid Oxisol. Communications in Soil Science and Plant Analysis, v.34, p.2045-2058, 2003.
GAUME, A.; MÄCHLER, F.; FROSSARD, E. Aluminium resistance in two cultivars of Zea mays L.: root exudation of organic acids and influence of phosphorus nutrition. Plant and Soil, v.234, p.7381, 2001.

GIACOMINI, S.J.; AITA, C.; HÜBNER, A.P.; LUNKES, A.; GUIDINI, E.; AMARAL, E.B. do. Liberação de fósforo e potássio durante a decomposição de resíduos culturais em plantio direto. Pesquisa Agropecuária Brasileira, v.38, p.1097-1104, 2003.

GONÇALVES, J.L.M.; FIRME, D.J.; NOVAIS, R.F.; RIBEIRO, A.C. Cinética de adsorção de fósforo em solos de cerrado. Revista Brasileira de Ciência do Solo, v.9, p.107-111, 1985.

KIEHL, J.C. Manual de edafologia: relações solo planta. São Paulo: Ceres, 1979. 246p.

MARSCHNER, H. Mineral nutrition of higher plants. New York: Academic Press, 1995. 674p.

MIYAZAWA, M.; PAVAN, M.A.; CALEGARI, A. Efeito de material vegetal na acidez do solo. Revista Brasileira de Ciência do Solo, v.17, p.411-416, 1993.

NOVAIS, F.R.; SMYTH, T.J. Fósforo em solo e planta em condições tropicais. Viçosa: UFV, 1999. 399p.

PERROTT, K.W.; MANSELL, G.P. Effect of fertilizer phosphorus and liming on inorganic and organic soil phosphorus fractions. New Zealand Journal of Agricultural Research, v.32, p.63-70, 1989.

RAIJ, B. van. Fertilidade do solo e adubação. Piracicaba: Ceres; Potafos, 1991. 343p.

RAIJ, B. van; ANDRADE, J.C.; CANTARELLA, H.; QUAGGIO, J.A. (Ed.). Análise química para avaliação da fertilidade de solos tropicais. Campinas: Instituto Agronômico, 2001. 285p.

ROSOLEM, C.A.; ASSIS, J.S.; SANTIAGO, A.D. Root growth and mineral nutrition of corn hybrids as affected by phosphorus and lime. Communications in Soil Science and Plant Analysis, v.25, p.2491-2499, 1994.

ROSOLEM, C.A.; BICUDO, S.J.; MARUBAYASHI, O.M. Soybean yield and root growth as affected by lime rate and quality. In: DATE, R.A. (Ed.). Plant-soil interactions at low pH: principles and management. Dordrecht: Kluwer, 1995. p.543-547.

ROSOLEM, C.A.; MARCELLO, C.S. Crescimento radicular e nutrição mineral da soja em função da calagem e adubação fosfatada. Scientia Agrícola, v.55, p.448-455, 1998.

SANTOS, H.P.; TOMM, G.O. Fertilidade do solo em rotação de culturas com trititicale. Revista Brasileira de Ciência do Solo, v.20, p.415-421, 1996.

WHALEN, J.K.; CHANG, C. Phosphorus sorption capacities of calcareous soils receiving cattle manure applications for 25 years. Communications in Soil Science and Plant Analysis, v.33, v.1011-1026, 2002.

Recebido em 5 de maio de 2004 e aprovado em 3 de novembro de 2004

Pesq. agropec. bras., Brasília, v.39, n.12, p.1231-1237, dez. 2004 